\title{
Kinetics of structure formation in PP/layered silicate nanocomposites
}

\author{
J. Hári ${ }^{1,2}$, Z. Dominkovics ${ }^{1,2}$, E. Fekete ${ }^{1,2}$, B. Pukánszky .,2* $^{*}$ \\ ${ }^{1}$ Laboratory of Plastics and Rubber Technology, Department of Physical Chemistry and Materials Science, Budapest \\ University of Technology and Economics, H-1521 Budapest, P.O. Box 91, Hungary \\ 2Institute of Materials and Environmental Chemistry, Chemical Research Center, Hungarian Academy of Sciences, \\ H-1525 Budapest, P.O. Box 17, Hungary
}

Received 30 April 2009; accepted in revised form 19 August 2009

\begin{abstract}
Polypropylene (PP)/organophilized montmorillonite (OMMT) and polypropylene/organophilized montmorillonite/maleic anhydride grafted polypropylene (MAPP) composites were prepared in an internal mixer under a wide range of processing conditions to study the kinetics of structure formation. Structure and properties were characterized by a variety of techniques. The gallery structure of the organophilic silicate changed in spite of the fact that no compatibilizer was added to PP/OMMT composites. Silicate reflection shifted towards smaller $2 \theta$ angles, broadened and its intensity decreased indicating intercalation. Transmission electron microscopy (TEM) micrographs even showed individual platelets at long mixing times. However, the extent and direction of changes in the gallery structure of the silicate did not justify those observed in properties. The analysis of the results and additional experiments proved that the degradation of the polymer also takes place during processing leading to the formation of carbonyl and/or carboxyl groups, as well as to the decrease of molecular weight. The modification of the chain structure of the polymer influences interfacial interactions and the intercalation process. Some properties are directly determined by molecular weight (rheological properties, elongation). Both the clay and the MAPP seem to accelerate degradation. Thermooxidative degradation must have disadvantageous effect during the application of PP nanocomposites and needs further study.
\end{abstract}

Keywords: nanocomposites, layered silicate, polypropylene, gallery structure, thermal degradation

\section{Introduction}

The interest in polymer/layered silicate nanocomposites is still large and intensive research is going on in many research groups in this field in spite of the fact that a real breakthrough has not been achieved yet. The strong interest is justified mainly by the claimed advantages of such nanocomposites. The complete exfoliation of the nanometer thick silicate layers is expected to result in the formation of a large interface which should result in exceptional properties [1-4]. Reinforcement at small clay content [1-4], decreased flammability [1-3] and permeability [1-4], improved heat deflection tem- perature [2, 4] are among the most often cited advantages of these materials.

Although the principles for the preparation of layered silicate nanocomposites are clear, complete exfoliation and the expected improvement in properties are rarely achieved. Quite a few controversial results are reported about the structure and properties of these materials as well as about the effect of various factors on them. The extent of exfoliation in a polymer/layered silicate nanocomposite is determined by thermodynamic and kinetic factors as discussed among others by Vaia and Giannelis $[5,6]$. Layered silicate nanocomposites are often

*Corresponding author, e-mail: bpukanszky@ mail.bme.hu (C) BME-PT 
complicated systems containing several components like the polymer, the silicate, the surfactant, and quite often also swelling and coupling agents or other additives to help exfoliation [7-14]. The competitive interactions acting among the various groups of the components are very difficult to estimate and control, which results in a wide range of structures often with inferior properties.

Similarly to the uncertainties related to the role and effect of interactions on the structure and properties of nanocomposites, the effect of kinetics, i.e. processing conditions, on structure development is also quite unclear. Some groups claim that processing conditions, or even preparation conditions do not influence the structure of the composites [15, 16], while others found a strong effect of processing $[17,18]$. For example Yilmazer and Ozden [16] compared the effect of three preparation conditions, i.e. in situ polymerization, melt compounding and a masterbatch method, and did not find any significant difference in structure and properties of polystyrene (PS) nanocomposites. On the other hand, Paul and co-workers [19-21] carried out a detailed study on polyamide 6 (PA6) nanocomposites using a single and three twin-screw extruders for processing and found a profound effect of conditions on the structure of the composites. Twin-screw extruders, longer residence time and medium shear resulted in larger extent of exfoliation than other conditions including high shear. Lertvimolnun and Vergnes [22-24] came practically to the same conditions finding a strong effect of kinetics on the structure and properties of PP/layered silicate nanocomposites. These results clearly show that the combination of thermodynamics and kinetics must determine the extent of exfoliation, as well as the resulting properties.

In view of the controversies cited above, the goal of our work was to study the effect of various factors on structure development in $\mathrm{PP} /$ layered silicate composites. The study focused mainly on kinetic factors, but interactions were also modified by the addition of a compatibilizer. The experiments were carried out in two series. In the first series several polypropylene homopolymers with different melt flow indices were used as matrix to modify shear stresses, and both the time and the rate of mixing were also changed. In the second series the same polymer was used in all experiments, but maleated PP was also added to assist exfoliation. The rate and time of mixing were changed also in this series at several levels. The structure of the composites was characterized by various methods and several properties were measured in order to identify the processes taking place during mixing and the most important factors influencing them.

\section{Experimental}

Five PP homopolymers produced by TVK, Hungary were used in the first series of experiments, the Tipplen H377 (PP90), H483 (PP65), H543 (PP40), H605 (PP30) and the H890 (PP03) grades. All polymers, their abbreviation and melt flow index (MFI) value are compiled in Table 1 together with the composition of the nanocomposites studied. The abbreviation is based on the MFI of the polymers. All polymers contained a commercial additive package except the H605 grade. The Nanofil 848 (N 848) product of Süd Chemie was used as silicate. This clay is coated with stearyl amine, its density is $1.8 \mathrm{~g} / \mathrm{cm}^{3}$, moisture content $2 \mathrm{wt} \%$, organic content $25 \mathrm{wt} \%$ and particle size $3 \mu \mathrm{m}$. Composition was the same in all experiments, 2 vol\% clay was added to the polymer. The Tipplen H 649 (PP25) grade was used as matrix polymer in the second series, the Nanofil SE 3000 (NSE 3000) silicate as reinforcement. The silicate was organophilized with $55 \mathrm{wt} \%$ distearyldimethyl amine, its density was $1.8 \mathrm{~g} / \mathrm{cm}^{3}$ and the average

Table 1. Characteristics of the polymers and composition of the nanocomposites studied

\begin{tabular}{|c|c|c|c|c|c|c|}
\hline \multicolumn{3}{|c|}{ Polymer } & \multicolumn{2}{|c|}{ MAPP } & \multicolumn{2}{|c|}{ Silicate } \\
\hline Trade name & Abbrev. & MFI $^{a}[g / 10 ~ \min ]$ & Type & vol\% & Type & vol\% \\
\hline Tipplen H 377 & PP90 & 9.0 & - & 0 & N 848 & 2 \\
\hline Tipplen $\mathrm{H} 483$ & PP65 & 6.5 & - & 0 & N 848 & 2 \\
\hline Tipplen H 543 & PP40 & 4.0 & - & 0 & N 848 & 2 \\
\hline Tipplen H 605 & PP30 & 3.0 & - & 0 & N 848 & 2 \\
\hline Tipplen H 890 & PP03 & 0.3 & - & 0 & N 848 & 2 \\
\hline Tipplen H 649 & PP25 & 2.5 & AR 504 & 20 & NSE 3000 & 1 \\
\hline
\end{tabular}

aDetermined at $230^{\circ} \mathrm{C}$ and $21.6 \mathrm{~N}$ 
particle size was less than $10 \mu \mathrm{m}$. A small molar mass maleated PP, Licomont AR 504 (AR 504, Clariant AG) was used as coupling agent to promote exfoliation. Its maleic anhydride content was $3.5 \mathrm{wt} \%$ and it had very low viscosity $(0.8 \mathrm{~Pa} \cdot \mathrm{s}$ at $\left.170{ }^{\circ} \mathrm{C}\right)$. The composites contained 1 vol\% clay and 20 vol\% MAPP in this series.

Composites were prepared in a Brabender W $50 \mathrm{EH}$ internal mixer attached to a Haake Rheocord EU $10 \mathrm{~V}$ driving unit at $190^{\circ} \mathrm{C}$. Charge volume was $42 \mathrm{~cm}^{3}$ in both series. Samples were prepared at the combination of 2, 5, 8, 10, 12, 15 and 20 min mixing time and $50 \mathrm{rpm}$, as well as at 10, 30, 70 and $100 \mathrm{rpm}$ and $8 \mathrm{~min}$ in the first series. Time changed in six $(5,10,15,30,45$ and $60 \mathrm{~min})$, while the rate of mixing in four (20,50, 80 and $120 \mathrm{rpm})$ steps and samples were prepared at all combinations of the parameters in the second series. The homogenized samples were compression molded into $1 \mathrm{~mm}$ thick plates using a Fontijne SRA 100 machine at $190{ }^{\circ} \mathrm{C}$ and $3 \mathrm{~min}$ preheating and 3 min compression time.

The gallery structure of the silicate was characterized by X-ray diffraction (XRD) using a Phillips PW 1830/PW 1050 equipment with $\mathrm{CuK}_{\alpha}$ radiation at $40 \mathrm{kV}$ and $35 \mathrm{~mA}$. The morphology of the samples was examined by transmission electron microscopy. 50-100 nm thick slices were cut at $-80{ }^{\circ} \mathrm{C}$ with a Leica Ultracut UCT microtome. TEM images were created with a Philips CM30 Twin STEM electron microscope fitted with Kevex Delta-Plus EDX and Gatan model 666 PEELS. Thin films of approximately $100 \mu \mathrm{m}$ thickness were compression molded from the composites for Fourier transform infrared spectroscopy (FTIR). The spectra were recorded using a Mattson Galaxy 3020 spectrometer (Unicam) in the $4000-400 \mathrm{~cm}^{-1}$ wavelength range with $4 \mathrm{~cm}^{-1}$ resolution in 16 scans. The color of the samples was measured using a Hunterlab Colourquest 45/0 apparatus and it was characterized by the yellowness index according to the ASTM D 1925 standard. Rheological measurements were carried out using a Paar Physica UDS 200 apparatus at $200{ }^{\circ} \mathrm{C}$ in oscillatory mode in the frequency range of $0.1-6001 / \mathrm{sec}$ on discs with $25 \mathrm{~mm}$ diameter and $0.5 \mathrm{~mm}$ thickness. The amplitude of the deformation was 5\%, which was in the linear elastic region checked by an amplitude sweep. The tensile properties of the samples were measured using an Instron 5566 appara- tus. Young's modulus was determined at $0.5 \mathrm{~mm} / \mathrm{min}$ cross-head speed. $50 \mathrm{~mm} / \mathrm{min}$ was used in the first and $5 \mathrm{~mm} / \mathrm{min}$ in the second series for the determination of tensile strength and elongation-at-break. All characteristics were derived from three parallel measurements.

\section{Results and discussion}

The results are presented in three sections. The two series are discussed separately first, then they are compared in a subsequent section to draw general conclusions from the study. Mostly the time dependence of properties will be shown to simplify discussion, practically the same conclusions can be drawn from the effect of the rate of processing on structure and properties.

\subsection{PP/OMMT composites}

The torque developing in the mixer was recorded during the preparation of the samples. Torque is proportional to shear stress, and since average shear rate is constant, it is proportional also to the viscosity of the melt. The torque recorded at the end of the homogenization is plotted against mixing time in Figure 1 for two composites with different matrices. The viscosity of the remaining three polymers was very similar to that of PP65, which was quite surprising since their MFI changed between 3 and

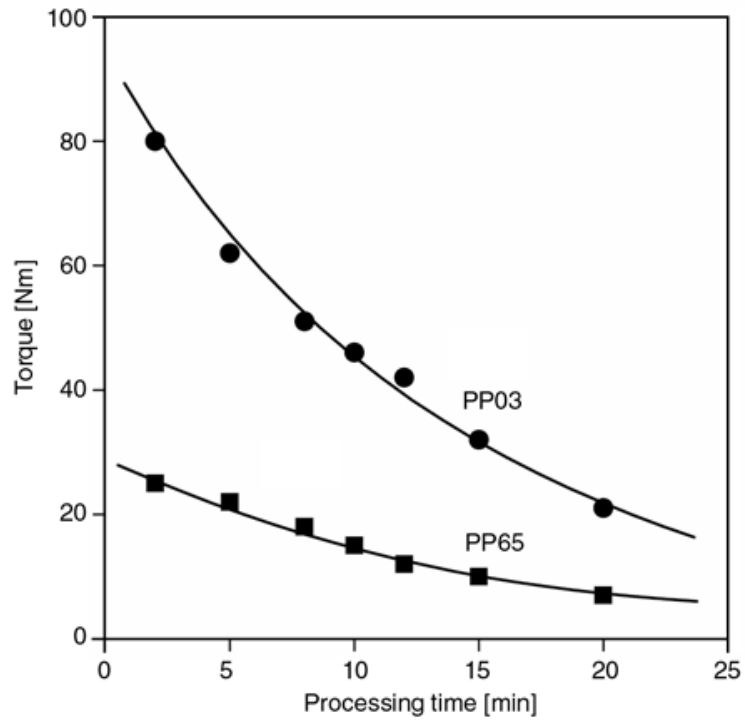

Figure 1. Effect of processing time and the molecular weight of the matrix polymer on the viscosity (torque) of layered silicate composite melts containing 2 vol\% OMMT 
$6.5 \mathrm{~g} / 10 \mathrm{~min}$. This similarity was observed in most properties, therefore we usually present only two correlations for the sake of clarity. However, the similarity of the behavior of the four polymers needs further study and explanation.

Torque decreases with time in both cases indicating changes in the structure of the composites. A definite explanation obviously cannot be given based on these correlations; one can only speculate on the possible reasons. Torque usually decreases in the first stage of the mixing until the material reaches constant temperature. In our case the decrease is continuous, thus it must be related to structural changes. Both the dispersed structure of the composite and the molecular structure of PP may change during mixing. The relatively large micron sized particles are evenly distributed in the matrix, but possible intercalation and/or exfoliation may also lead to changes in viscosity. One would expect an increase in viscosity with exfoliation, since exfoliation creates new surfaces, and strong interaction should lead to the formation of an interphase with decreased mobility. On the other hand, we know that the surface free energy of organophilic MMT is small [25], thus weak interaction with the clay may result in the disruption of entanglements and weaker interaction among the chains, like in PVC nanocomposites [26]. Naturally this latter explanation is rather improbable considering the very small surface tension of PP and the resulting weak interactions in this polymer.

Both of the polymers contain a commercial additive package, i.e. they are sufficiently stabilized for normal processing and application purposes. However, we know that PP is rather sensitive to degradation which proceeds through $\beta$-scission in this polymer resulting in the decrease of molecular weight. If the organoclay catalyses the chemical reactions occurring during the processing of the polymer and promotes degradation, chains scission may occur and molecular weigh decreases as a result. Only the analysis of further results may answer these questions.

Although extensive exfoliation is not expected in the absence of a compatibilizer in these PP/OMMT composites, structural changes may occur, which can influence their properties, including viscosity. The WAXS patterns of the composites prepared from PP03 with 2 vol\% OMMT are presented in Figure 2. Although not very dramatic, but a clear

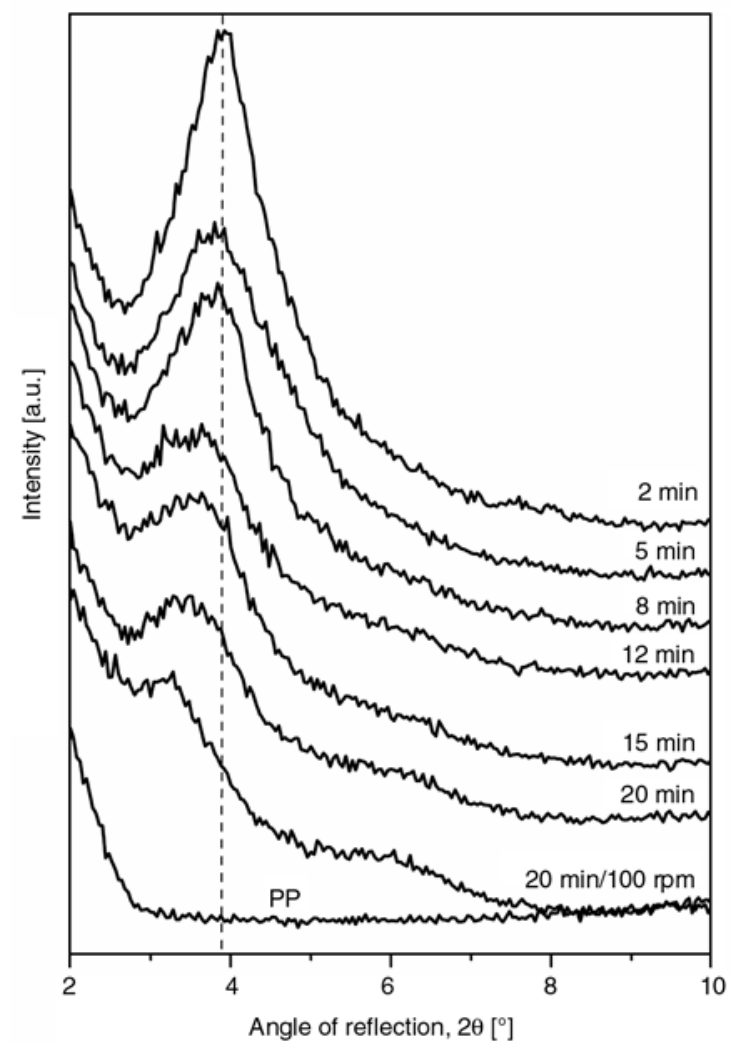

Figure 2. WAXS patterns of PP03/OMMT composites processed under various conditions. See shift and broadening of the silicate reflection.

change can be observed in the traces. The characteristic peak of the silicate broadens and shifts towards smaller $2 \theta$ angles. This latter change is usually explained by the intercalation of the polymer into the galleries of the silicate, while the broadening indicates less regular stacking of the layers. Accordingly, the WAXS study indicates changes in the gallery structure of the polymer and/or limited exfoliation. In order to check the dispersed structure of the composites TEM micrographs were taken from selected samples. These also corroborate our conclusion that structure changes somewhat during the processing of the composites. A very large particle of at least 5 micron size is seen in the TEM micrograph taken from the PP65 composite after 5 min processing time (Figure 3a). The particle is very compact, intercalation or exfoliation cannot be observed at all. On the other hand, structure changes considerably after $20 \mathrm{~min}$ homogenization as Figure $3 \mathrm{~b}$ shows. The size of this particle is much smaller, its structure is looser and individual platelets as well as smaller fragments are also visible in the micrograph (see arrows). Longer mixing obviously resulted in the transformation of structure. 


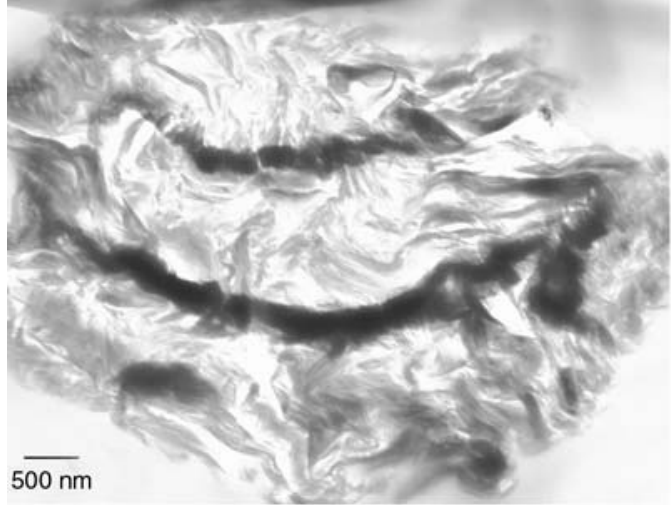

a)

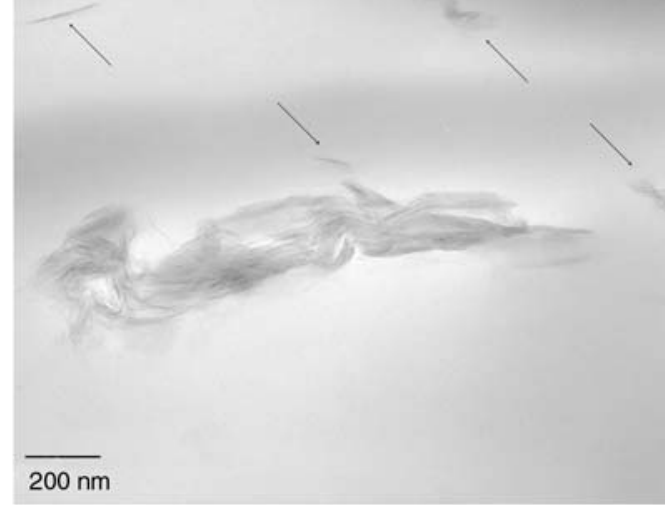

b)

Figure 3. Changes in the gallery structure of the silicate with increasing processing time. PP65/2 vol\% OMMT. a) 5 min, $50 \mathrm{rpm}$, b) $20 \mathrm{~min}, 50 \mathrm{rpm}$. Arrows indicate individual platelets or smaller particles.

However, these changes are not necessarily related to the decrease of viscosity during mixing. On the other hand, a very close correlation is obtained if we plot the intensity of the silicate reflection, characterized by the area under the peak, against the torque measured at the end of mixing (Figure 4). The tendency is clear in spite of the small differences observed among the polymers with smaller molecular weights. The arrow in the figure indicates increasing processing time. Accordingly, gallery distance increases (not shown) and the intensity of the reflection decreases with decreasing viscosity. Obviously the magnitude of shear forces does not play a determining role in these structural changes, since it decreases continuously with increasing processing time. Larger mobility of the smaller molecules may facilitate diffusion into the

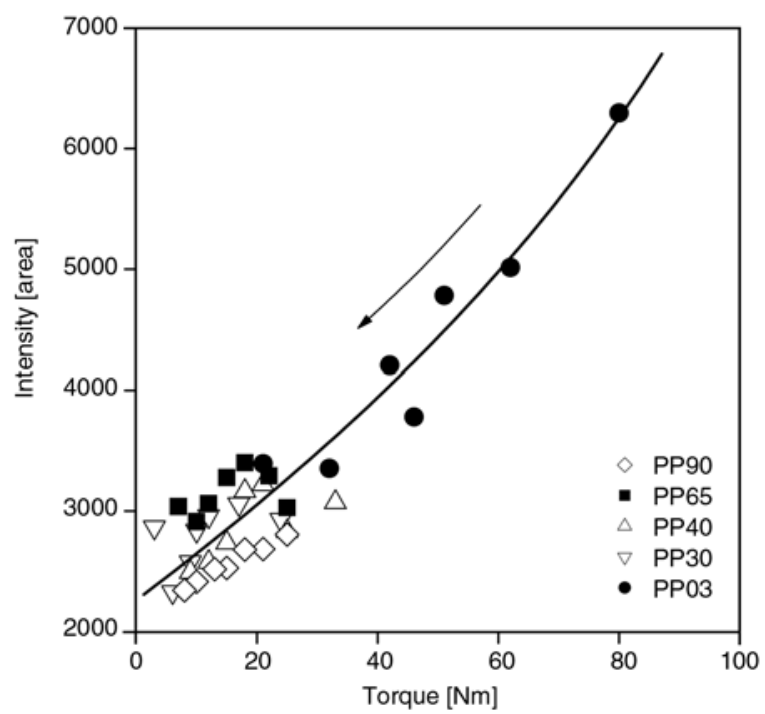

Figure 4. Correlation between the intensity of the silicate reflection and the torque (viscosity) measured at the end of the mixing galleries, but the degradation of the polymer might modify interactions as well.

The changes in the structure of the composites resulted in the modification of properties as well. The Young's modulus of composites prepared with three matrices is plotted against mixing time in Figure 5. The broken line in the figure indicates the stiffness of a $\mathrm{PP} / \mathrm{CaCO}_{3}$ composite containing $5 \mathrm{vol} \%$ filler. $\mathrm{CaCO}_{3}$ does not exfoliate thus it is used as reference for non-exfoliated PP/OMMT composites. Stiffness is determined by the crystalline structure of the polymer and by the extent of exfoliation. The correlations are very difficult to explain. Modulus increases with increasing MFI of the matrix, which would indicate the effect of chain mobility. However, the decrease of stiffness cannot be explained at all, it must be related to changing crystalline structure or increased interaction hinder-

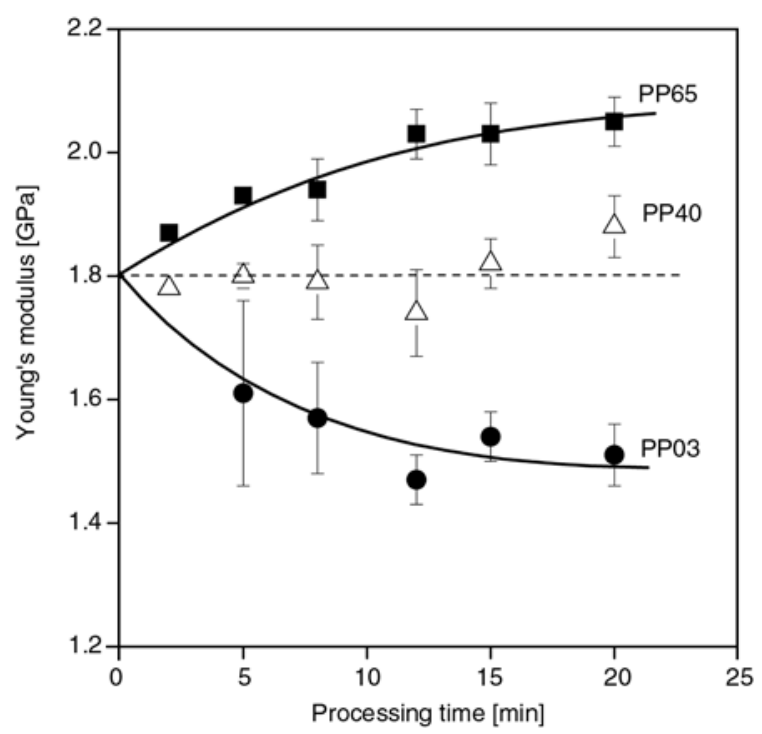

Figure 5. Effect of matrix properties and processing time on the stiffness of PP/OMMT composites 
ing the crystallization of the polymer (see PP03). Both the position of the silicate reflection and its intensity decreased indicating increased intercalation and/or some exfoliation, confirmed also by the TEM study. These changes should have resulted in an increase and not a decrease in stiffness.

Figure 6 presents changes in the relative deformability of the samples with increasing processing time for composites prepared with three matrices. The elongation-at-break values of the neat polymers differ considerably due to their dissimilar molecular weight, thus relative values must be used for comparison. The results further complicate the situation and finding a plausible explanation for the changes. One would expect some correlation between molecular weight and changes in deformability here too, but the PP30 matrix maintains the largest deformability, while the PP03 polymer with the largest initial elongation-at-break has an intermediate value. At longer processing times the deformability of the PP65 polymer is close to zero. The relative order of the polymers is very difficult to understand, since the PP65 and PP03 polymers contained commercial stabilizer packages, while the PP30 polymer was not stabilized. Nevertheless, after considering all the results presented above, and those not shown, we may conclude that the degradation of the polymers and the resulting changes in their molecular structure may play a role in the determination of structure and properties.

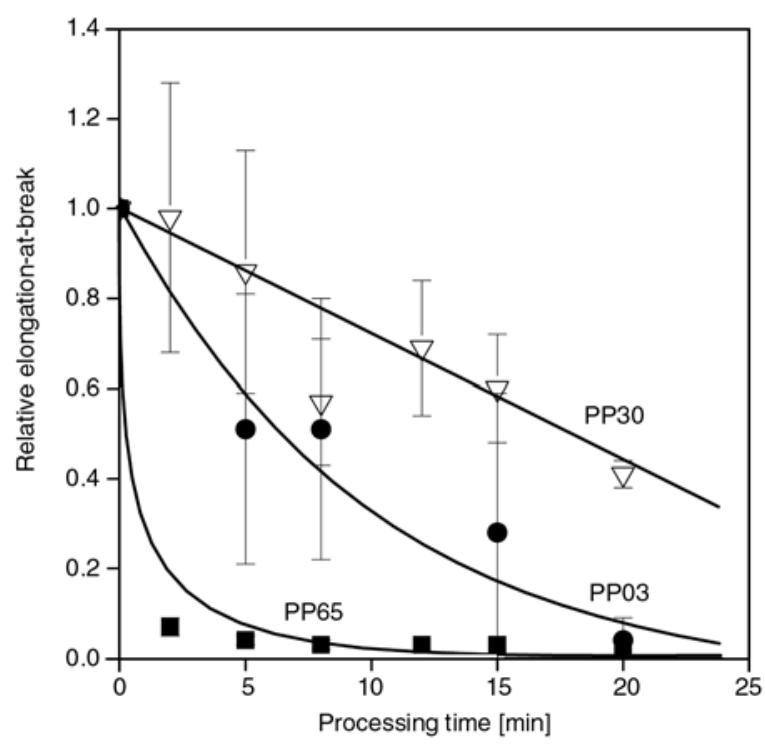

Figure 6. Changes in the relative elongation-at-break values of PP/OMMT composites with the MFI of the matrix and with increasing processing time
In order to check this hypothesis, FTIR spectra were recorded on the neat polymers and on the composites. Evaluation was rather difficult in the latter case because of the intensive absorbance of the silicate. Nevertheless a peak was detected in the spectra at $1714 \mathrm{~cm}^{-1}$ in the range where usually carbonyl and carboxyl groups absorb. The intensity of this vibration is plotted against processing time in Figure 7. The number of carbonyl groups seems to increase considerably during processing which supports our hypothesis about the degradation of the polymer. In a further attempt to prove the role of degradation, we introduced additional amounts of stabilizer into the composite $(0.1 \mathrm{wt} \%$ Irganox 1010). The change of torque with time is presented in Figure 8 for composites prepared with the PP03 polymer with and without additional stabilization. The difference is clear, viscosity decreases somewhat at the shorter processing times, most probably because of increasing temperature, and remains more or less constant afterwards for the stabilized sample. We must mention here that the elongationat-break values change similarly with stabilization indicating the clear effect of molecular weight and degradation in the determination of this property. We can conclude that PP degrades in smaller or larger extent during the production of these layered silicate composites. The extent of degradation must depend on the efficiency of stabilization. The clay seems to accelerate degradation. Changing molecular structure modifies chain structure, which influ-

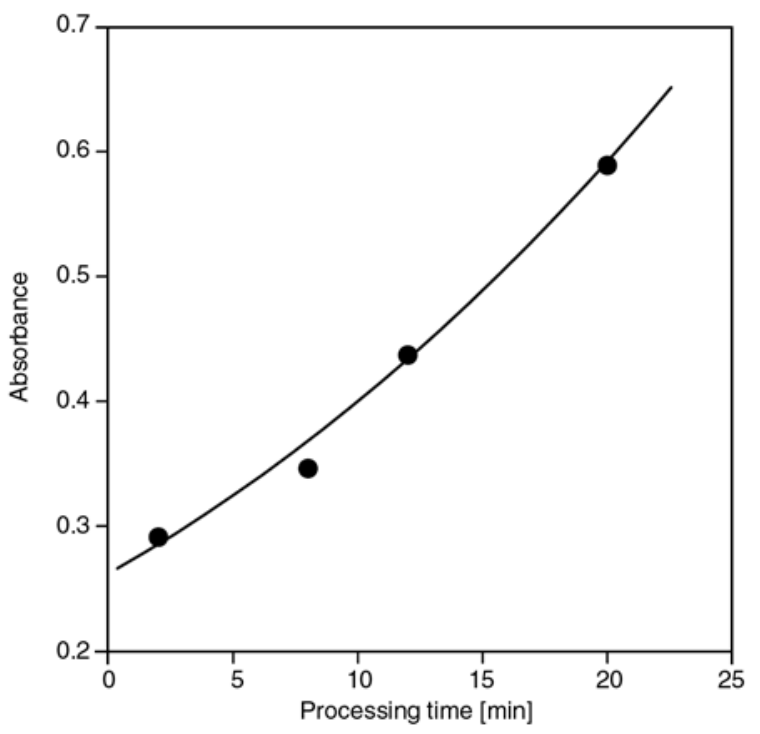

Figure 7. Increasing carbonyl content of PP03/OMMT composites with increasing time of homogenization 


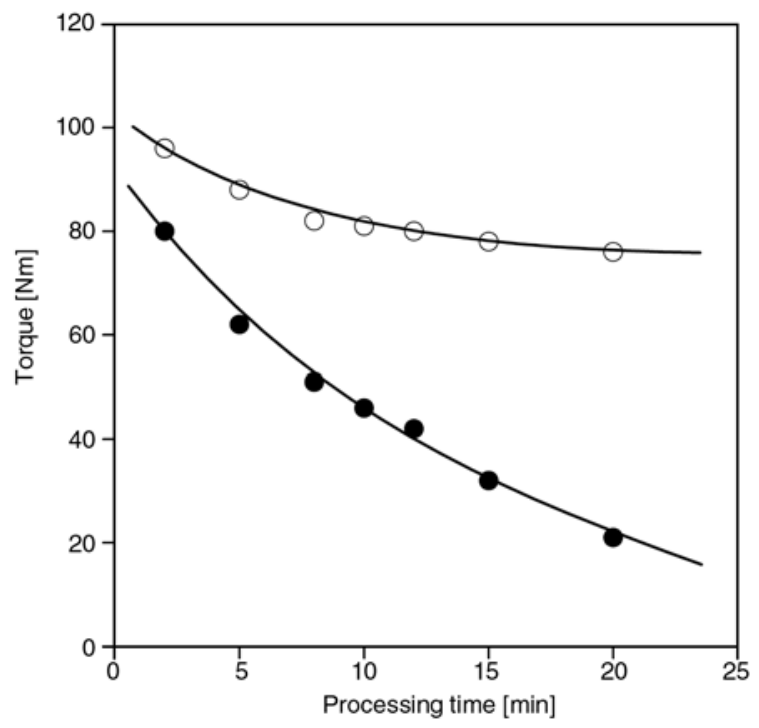

Figure 8. Effect of additional stabilization on the viscosity (torque) of PP03/PP composites. (•) without additional stabilization, (o) with $0.1 \mathrm{wt} \%$ Irganox 1010 stabilizer.

ences interactions and mobility, but also the structure of the composites. The degree of exfoliation is very limited but some intercalation definitely occurs in the studied PP/OMMT composites. The role of the clay in degradation processes needs further investigation.

\subsection{PP/OMMT/MAPP composites}

PP nanocomposites are practically always prepared with a compatibilizer in order to facilitate exfoliation. Exfoliation was very limited in the absence of MAPP indeed, as shown in the previous section. In the next series of experiments we added a small molecular weight MAPP compatibilizer with large functionality $[27,28]$ to the composites. The effect of the compatibilizer on the gallery structure of the composites is shown in Figure 9. The silicate peak completely disappears already after 5 min mixing time even under very moderate shear conditions (20 rpm). Further changes cannot be observed in the pattern with increasing processing load (60 min, $120 \mathrm{rpm})$. Some authors claim complete exfoliation based on the disappearance of the silicate reflection $[29,30]$, but several studies proved that this is not true [31,32]. Nevertheless, the gallery structure of the composite changed considerably in the presence of the compatibilizer. This change is confirmed by the TEM micrograph taken from the sample processed at $50 \mathrm{rpm}$ for $10 \mathrm{~min}$ (Figure 10).

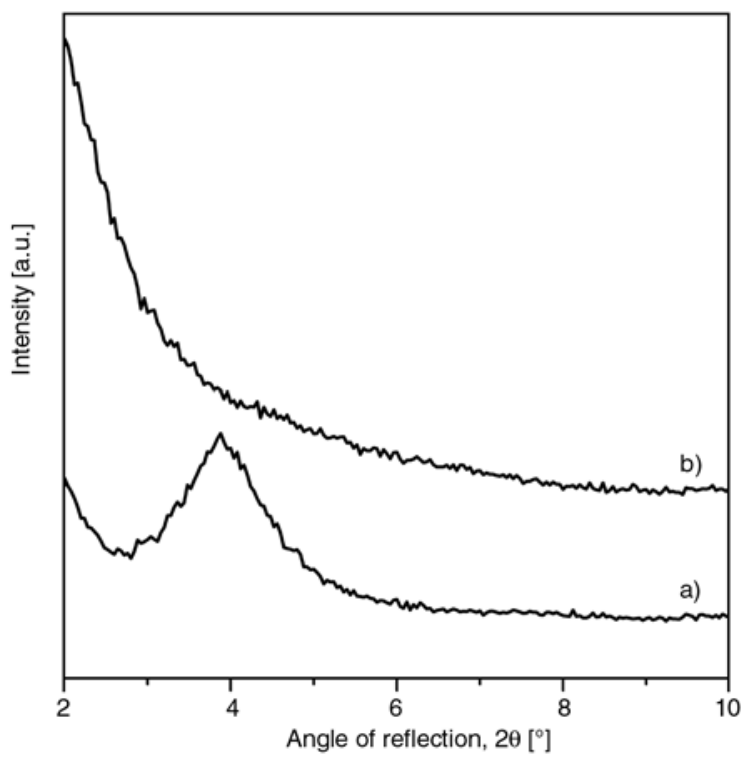

Figure 9. Influence of maleated PP compatibilizer on the gallery structure of the silicate in PP/OMMT nanocomposites. See the disappearance of the silicate reflection. a) PP/OMMT, $10 \mathrm{~min}$, $50 \mathrm{rpm}, \mathrm{b}) \mathrm{PP} / \mathrm{OMMT} / \mathrm{MAPP}, 10 \mathrm{~min}, 50 \mathrm{rpm}$.

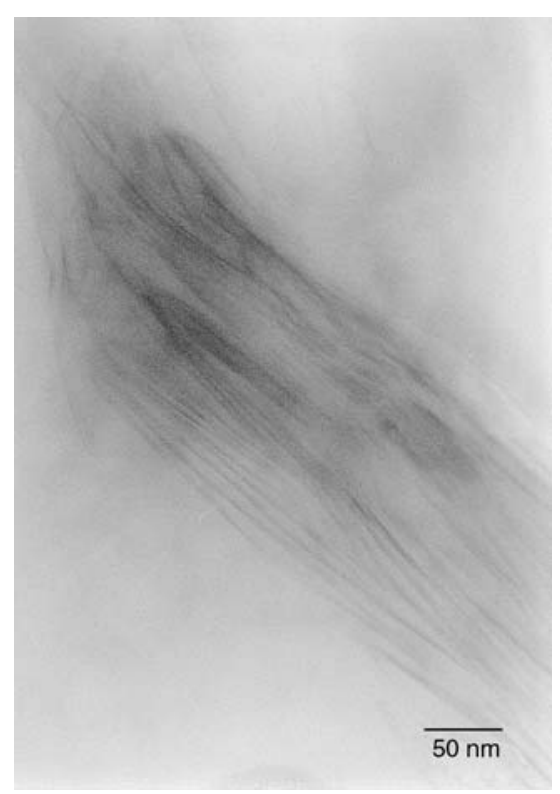

Figure 10. TEM micrograph taken from a silicate particle in a PP/OMMT/MAPP nanocomposite. See the loose structure, changing platelet density and individual platelets

A relatively large particle, but with a very loose structure can be observed in the figure. The density of platelets increases towards the center, gallery distance is larger at the edges and at the lower end of the particle. A few individual layers can also bee seen in the upper left corner. The micrograph proves that the disappearance of the silicate does not indicate complete exfoliation, but the compati- 
bilizer loosens up the structure and helps intercalation as well as exfoliation.

Unfortunately, the proper evaluation of properties is very difficult when this small molecular weigh compound is used as compatibilizer. Especially the rheological properties change drastically in its presence. However, the time dependence of viscosity as well as the comparison of the viscosity of $\mathrm{PP} /$ MAPP blends to that of PP/OMMT/MAPP composites indicates that molecular weight decreases with increasing processing time (Figure 11), but

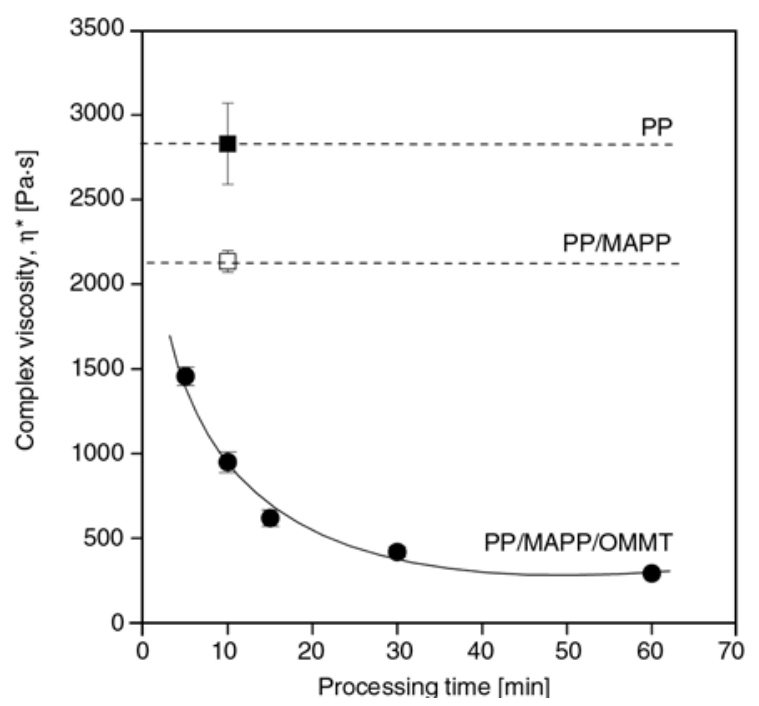

Figure 11. Effect of the compatibilizer, the clay and processing time on the complex viscosity of PP/OMMT/MAPP nanocomposites determined at $1 \mathrm{~s}^{-1}$ frequency. See the detrimental effect of the components.

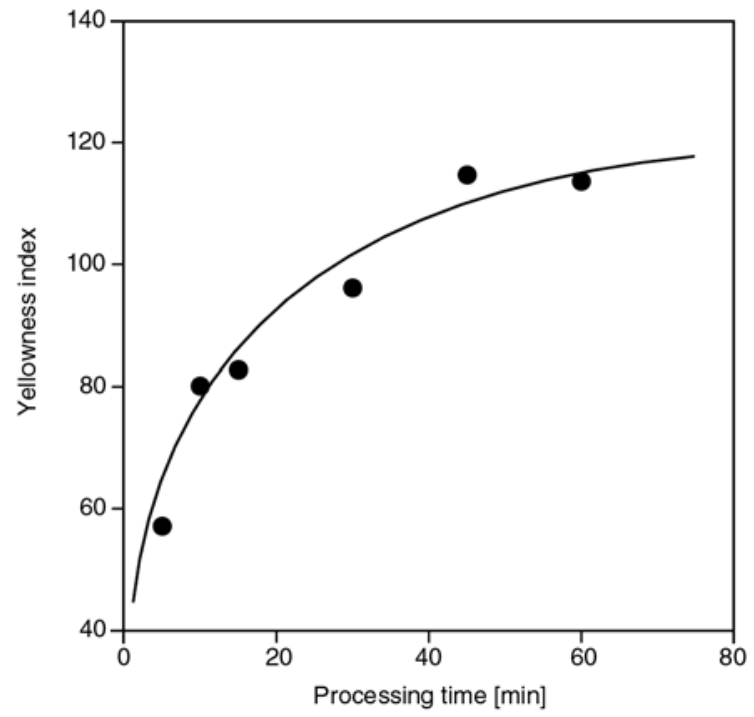

Figure 12. Increasing color of PP/OMMT/MAPP nanocomposites with increasing processing time at $50 \mathrm{rpm}$ proving chemical reactions and degradation also with increasing shear rate (not shown). This result confirms and strongly supports our previous observation about the possible degradation of the polymer during the processing of these layered silicate composites. A further proof for degradation is supplied by the changes in the color of the composites with processing conditions. The yellowness index of the composite processed at $50 \mathrm{rpm}$ is plotted as a function of mixing time in Figure 12. The drastic increase in color is a clear proof of chemical reactions occurring in the composite during processing. The results of two independent series of measurements unambiguously prove that degradation of the polymer occurs and influences properties.

\subsection{Comparison, discussion}

The stability of polymer/layered silicate nanocomposites is an often discussed topic in the literature, but not in the context encountered here. Layered silicates are claimed to improve thermal stability and the claim is usually supported by thermal gravimetric (TGA) measurements [33, 34]. Degradation temperature is supposed to increase due to the formation of a silicate layer, which hinders the diffusion of flammable gases out of and that of the oxygen into the composite. This phenomenon might be important in the burning of plastic products and flame retardancy, but not during the processing and use of such composites. Although the deteriorating effect of the components (OMMT, MAPP) was shown on the light stability of PP/layered silicate composites [35, 36], very few papers were published on thermooxidative stability. However, degradation is obviously accelerated by the organoclay and probably also by the functionalized polymer shown by both series of measurements of this study. Changing molecular structure of PP influences properties and complicates the evaluation of structure-property correlations.

The apparently contradictory results reported in the previous two sections are the results of complex processes including degradation, which modifies interactions and the kinetics of intercalation. The degradation of the polymer leads to the formation carbonyl and carboxyl groups even in the presence of stabilizers. Only a few carboxyl groups were shown to change interactions drastically in $\mathrm{PP} / \mathrm{CaCO}_{3}$ composites [37-39]. The increasing 
number of carbonyl groups changes the interaction of the polymer with the organophilic silicate and decreasing chain length leads to increased mobility and faster diffusion. These result in increased intercalation in PP/OMMT composites (Figures 2 and 3). However, stronger interaction modifies also crystallization and crystalline structure leading to a diverse response of modulus to changing processing conditions (Figure 5). Deformability is determined mainly by molecular weight (Figure 6).

In spite of the increasing number of carbonyl groups, intercalation and exfoliation is limited in PP/OMMT composites. The inclusion of MAPP assists intercalation, but complete exfoliation is not achieved even in this case. Degradation processes seem to be significant also in the presence of the functionalized polymer. The small molecular weight of MAPP and degradation further complicates the identification of the main factors determining structure and properties in these PP/ OMMT/MAPP nanocomposites. Targeted experiments with proper experimental design are needed to separate the effects discussed here and resolve the complexity of the processes and factors playing a role in the preparation of PP nanocomposites.

\section{Conclusions}

The gallery structure of the organophilic silicate changed in spite of the fact that no compatibilizer was added to PP/OMMT nanocomposites. Silicate reflection shifted towards smaller $2 \theta$ angles, broadened and its intensity decreased indicating intercalation. TEM micrographs even showed individual platelets at long mixing times. However, the extent and direction of changes in the gallery structure of the silicate did not justify those observed in properties. The analysis of the results and additional experiments proved that the degradation of the polymer also takes place during processing leading to the formation of carbonyl and/or carboxyl groups, as well as to the decrease of molecular weight. The modification of chain structure influences interfacial interactions and the intercalation process. Some properties are directly determined by molecular weight (rheological properties, elongation). Both the clay and the functionalized polymer seem to accelerate degradation. Thermooxidative degradation must have disadvantageous effect during the application of PP nanocomposites and needs further study.

\section{Acknowledgements}

TVK, Süd Chemie and Clariant are acknowledged for the donation of the raw materials. We would like to express our sincere gratitude to Ágnes Ábrányi, László Százdi and Balázs Imre for their help in sample preparation and measurement. The authors are indebted to Gyeong-Man Kim for the preparation of some of the TEM micrographs. The project was partially financed by the National Scientific Research Fund of Hungary (OTKA K68748 and K67936), the support is highly appreciated.

\section{References}

[1] Alexandre M., Dubois P.: Polymer-layered silicate nanocomposites: Preparation, properties and uses of a new class of materials. Materials Science and Engineering R: Reports, 28, 1-63 (2000). DOI: $10.1016 / \mathrm{S} 0927-796 \mathrm{X}(00) 00012-7$

[2] Ray S. S., Okamoto M.: Polymer /layered silicate nanocomposites: A review from preparation to processing. Progress in Polymer Science, 28, 1539-1641 (2003).

DOI: $10.1016 /$ j.progpolymsci.2003.08.002

[3] LeBaron P. C., Wang Z., Pinnavaia T. J.: Polymer-layered silicate nanocomposites: An overview. Applied Clay Science, 15, 11-29 (1999). DOI: $\underline{10.1016 / \mathrm{S} 0169-1317(99) 00017-4}$

[4] Pinnavaia T. J., Beall G. W.: Polymer-clay nanocomposites. Wiley, New York (2001).

[5] Vaia R. A., Giannelis E. P.: Lattice model of polymer melt intercalation in organically-modified layered silicates. Macromolecules, 30, 7990-7999 (1997).

DOI: $10.1021 / \mathrm{ma} 9514333$

[6] Vaia R. A., Giannelis E. P.: Polymer melt intercalation in organically-modified layered silicates: Model predictions and experiment. Macromolecules, 30, 80008009 (1997).

DOI: $10.1021 / \mathrm{ma9603488}$

[7] Reichert P., Hoffmann B., Bock T., Thomann R., Mülhaupt R., Friedrich C.: Morphological stability of poly(propylene) nanocomposites. Macromolecular Rapid Communications, 22, 519-523 (2001). DOI: $10.1002 / 1521-3927(20010401) 22: 7<519::$ AIDMARC519>3.0.CO;2-W

[8] Kawasumi M., Hasegawa N., Kato M., Usuki A., Okada A.: Preparation and mechanical properties of polypropylene-clay hybrids. Macromolecules, 30, 6333-6338 (1997).

DOI: $\underline{10.1021 / \mathrm{ma} 961786 \mathrm{~h}}$ 
[9] Kim K. N., Kim H., Lee J. W.: Effect of interlayer structure, matrix viscosity and composition of a functionalized polymer on the phase structure of polypropylene-montmorillonite nanocomposites. Polymer Engineering and Science, 41, 1963-1969 (2001). DOI: $10.1002 /$ pen.10892

[10] Usuki A., Kato M., Okada A., Kurauchi T.: Synthesis of polypropylene-clay hybrid. Journal of Applied Polymer Science, 63, 137-139 (1997).

DOI: $10.1002 /($ SICI) 1097-4628(19970103)63:1<137:: AID-APP15>3.0.CO;2-2

[11] Hasegawa N., Kawasumi M., Kato M., Usuki A., Okada A.: Preparation and mechanical properties of polypropylene-clay hybrids using maleic anhydride intercalation-modified polypropylene oligomer. Journal of Applied Polymer Science, 67, 87-90 (1998).

DOI: $10.1002 /($ SICI $) 1097-4628(19980103) 67: 1<87:$ : AID-APP10>3.0.CO;2-2

[12] Zhang Y-Q., Lee J. H., Jang H-J., Nah C-W.: Preparing PP/clay nanocomposites using a swelling agent. Composites Part B: Engineering, 35, 133-138 (2004). DOI: $10.1016 /$ S1359-8368(03)00068-4

[13] Liu X. H., Wu Q. J.: PP/claynanocomposites prepared by grafting-melt intercalation. Polymer, 42, 1001310019 (2001).

DOI: $10.1016 / \mathrm{S} 0032-3861(01) 00561-4$

[14] Ishida H., Campbell S., Blackwell J.: General approach to nanocomposite preparation. Chemistry of Materials, 12, 1260-1267 (2000). DOI: $10.1021 / \mathrm{cm} 990479 \mathrm{y}$

[15] Poisson C., Guerengomba J., Lacrampe M. F., Krawczak P., Gupta B., Miri V., Lefebvre J. M.: Mechanical, optical and barrier properties of PA6/nanoclaybased single- and multilayer blown films. Polymers and Polymer Composites, 16, 349-358 (2008).

[16] Yilmazer U., Ozden Y.: Polystyrene-organoclay nanocomposites prepared by melt intercalation, in situ, and masterbatch methods. Polymer Composites, 27, 249-255 (2006).

DOI: $10.1002 /$ pc. 20191

[17] Hasegawa N., Usuki A.: Silicate layer exfoliation in polyolefin/clay nanocomposites based on maleic anhydride modified polyolefins and organophilic clay. Journal of Applied Polymer Science, 93, 464-470 (2004).

DOI: 10.1002/app.20459

[18] Modesti M., Lorenzetti A., Bon D., Besco S.: Effect of processing conditions on morphology and mechanical properties of compatibilized polypropylene nanocomposites. Polymer, 46, 10237-10245 (2005).

DOI: $10.1016 /$ j.polymer.2005.08.035

[19] Dennis H. R., Hunter D. L., Chang D. H., Kim S. Y., White J. L., Cho J. W., Paul D. R.: Nanocomposites: The importance of processing. Plastics Engineering. 57, 56-60 (2001).
[20] Dennis H. R., Hunter D. L., Chang D. H., Kim S. Y., White J. L., Cho J. W., Paul D. R.: Effect of melt processing conditions on the extent of exfoliation in organoclay-based nanocomposites. Polymer, 42, 9513-9522 (2001).

DOI: $10.1016 / \mathrm{S} 0032-3861(01) 00473-6$

[21] Chavarria F., Shah R. K., Hunter D. L., Paul D. R.: Effect of melt processing conditions on the morphology and properties of nylon 6 nanocomposites. Polymer Engineering and Science, 47, 1847-1864 (2007). DOI: 10.1002/pen.20894

[22] Lertwimolnun W., Vergnes B.: Influence of compatibilizer and processing conditions on the dispersion of nanoclay in a polypropylene matrix. Polymer, 46, 3462-3471 (2005).

DOI: 10.1016/j.polymer.2005.02.018

[23] Lertwimolnun W., Vergnes B.: Effect of processing conditions on the formation of polypropylene/organoclay nanocomposites in a twin screw extruder. Polymer Engineering and Science, 46, 314-323 (2006). DOI: 10.1002/pen.20458

[24] Lertwimolnun W., Vergnes B.: Influence of screw profile and extrusion conditions on the microstructure of polypropylene/organoclay nanocomposites. Polymer Engineering and Science, 47, 2100-2109 (2007). DOI: 10.1002/pen.20934

[25] Kádár F., Százdi L., Fekete E., Pukánszky B.: Surface characteristics of layered silicates: Influence on the properties of clay/polymer nanocomposites. Langmuir, 22, 7848-7854 (2006).

DOI: $10.1021 / \mathrm{la} 060144 \mathrm{c}$

[26] Pozsgay A., Csapó I., Százdi L., Pukánszky B.: Preparation, structure, and properties of $\mathrm{PVC} /$ montmorillonite nanocomposites. Materials Research Innovations, 8, 138-139 (2004).

[27] Kaempfer D., Thomann R., Mülhaupt R.: Melt compounding of syndiotactic polypropylene nanocomposites containing organophilic layered silicates and in situ formed core/shell nanoparticles. Polymer, 43, 2909-2916 (2002).

DOI: 10.1016/S0032-3861(02)00113-1

[28] Misheva M., Djourelov N., Zamfirova G., Gaydarov V., Cerrada M. L., Rodríguez-Amor V., Pérez E.: Effect of compatibilizer and electron irradiation on free-volume and microhardness of syndiotactic polypropylene/clay nanocomposites. Radiation Physics and Chemistry, 77, 138-145 (2008). DOI: $10.1016 /$ j.radphyschem.2007.04.007

[29] Hasegawa N., Okamoto H., Kawasumi M., Kato M., Tsukigase A., Usuki A.: Polyolefin-clay hybrids based on polyolefins and organophilic clay. Macromolecular Materials and Engineering, 280, 76-79 (2000). DOI: $10.1002 / 1439-2054(20000801) 280: 1<76::$ AIDMAME76>3.0.CO;2-\# 
[30] Tang Y., Hu Y., Wang S. F., Gui Z., Chen Z. Y.: Preparation of poly(propylene)/clay layered nanocomposites by melt intercalation from pristine montmorillonite (MMT). Polymers for Advanced Technologies, 14, 733-737 (2003). DOI: $10.1002 /$ pat.420

[31] Wagener R., Reisinger T. J. G.: A rheological method to compare the degree of exfoliation of nanocomposites. Polymer, 44, 7513-7518 (2003).

DOI: 10.1016/j.polymer.2003.01.001

[32] Morgan A. B., Gilman J. W.: Characterization of polymer-layered silicate (clay) nanocomposites by transmission electron microscopy and X-ray diffraction: A comparative study. Journal of Applied Polymer Science, 87, 1329-1338 (2003).

DOI: 10.1002/app.11884

[33] Zhang J., Jiang D. D., Wilkie C. A.: Thermal and flame properties of polyethylene and polypropylene nanocomposites based on an oligomerically-modified clay. Polymer Degradation and Stability, 91, 298-304 (2006).

DOI: 10.1016/j.polymdegradstab.2005.05.006

[34] Zhang Y-Q., Lee J-H., Rhee J. M., Rhee K. Y.: Polypropylene-clay nanocomposites prepared by in situ grafting-intercalating in melt. Composites Science and Technology, 64, 1383-1389 (2004).

DOI: 10.1016/j.compscitech.2003.10.014
[35] Mailhot B., Morlat S., Gardette J-L., Boucard S., Duchet J., Gérard J-F.: Photodegradation of polypropylene nanocomposites. Polymer Degradation and Stability, 82, 163-167 (2003). DOI: $10.1016 / \mathrm{S} 0141-3910(03) 00179-4$

[36] Morlat-Therias S., Mailhot B., Gonzalez D., Gardette J-L.: Photooxidation of polypropylene/montmorillonite nanocomposites. 2. Interactions with antioxidants. Chemistry of Materials, 17, 1072-1078 (2005). DOI: $10.1021 / \mathrm{cm} 0401721$

[37] Demjén Z., Pukánszky B., Nagy J. Jr.: Possible coupling reactions of functional silanes and polypropyelene. Polymer, 40, 1763-1773 (1998). DOI: $10.1016 /$ S0032-3861(98)00396-6

[38] Demjén Z., Pukánszky B., Nagy J. Jr.: Evaluation of interfacial interaction in polypropylene/surface treated $\mathrm{CaCO}_{3}$ composites. Composites Part A: Applied Science and Manufacturing, 29, 323-329 (1998). DOI: $\underline{10.1016 / \text { S1359-835X(97)00032-8 }}$

[39] Demjén Z., Pukánszky B.: Effect of surface coverage of silane treated $\mathrm{CaCO}_{3}$ on the tensile properties of polypropylene composites. Polymer Composites, 18, 741-747 (1997).

DOI: $\underline{10.1002 / p c .10326}$ 